\title{
Reflection of disease activity in rheumatoid arthritis by indices of activation of the classical complement $\frac{\overline{\frac{\sigma}{\bar{\sigma}}}}{2}$ pathway
}

V A MAKINDE, G SENALDI, A S M JAWAD, H BERRY, AND D VERGANI From the Departments of Immunology and Rheumatology, King's College School of Medicine and Dentistry London

SUMMARY Levels of $\mathrm{C} 4 \mathrm{~d}$, a fragment of $\mathrm{C} 4$ generated during activation of the classica $\mathrm{E}_{\omega}^{+}$ complement pathway, were measured in the plasma of 77 patients with rheumatoid arthritis an中 30 healthy subjects. Disease activity was judged according to Ritchie's articular index to be mildlyg active in 31 (group 1), moderately active in 29 (group 2), and severely active in 17 patients (group3). Plasma levels of $\mathrm{C} 3 \mathrm{~d}$, a fragment of $\mathrm{C} 3$, and serum levels of $\mathrm{C} 4, \mathrm{C} 3$, and immune complexe were also measured. The ratios $C 4 d / C 4$ and $C 3 d / C 3$ were calculated. The $C 4 d / C 4$ and $C 3 d / C 3=$ ratios and the levels of circulating immune complexes correlated with the degree of disease $\overrightarrow{0}$ activity without significantly departing from linear trend and discriminated between patients with different grades of disease activity. C4d, C3d, C4, and C3 also correlated with disease activity bur in a non-linear relationship. A significant correlation was found between $\mathrm{C} 4 \mathrm{~d}$ and $\mathrm{C} 3 \mathrm{~d}$, and between $\mathrm{C} 4 \mathrm{~d} / \mathrm{C} 4$ and $\mathrm{C} 3 \mathrm{~d} / \mathrm{C} 3$. $\mathrm{C} 4 \mathrm{~d}$ and $\mathrm{C} 4 \mathrm{~d} / \mathrm{C} 4$ also correlated with circulating immunes complexes. These results indicate that indices of $\mathrm{C} 4$ and $\mathrm{C} 3$ activation, in particular the ratios $\mathrm{C} 3 \mathrm{~d} / \mathrm{C} 3$ and $\mathrm{C} 4 \mathrm{~d} / \mathrm{C} 4$, provide a sensitive assessment of disease activity in rheumatoid arthritis $\stackrel{\mathbb{Q}}{\varrho}$ and confirm the major part played by the classical complement pathway in the pathogenesis o $\overrightarrow{\vec{b}}$ this disease.

Activation of the complement system represents a major mechanism of inflammation in a variety of connective tissue disorders. ${ }^{1}$ Complement involvement in rheumatoid arthritis has been demonstrated by the finding of depressed levels of complement factors in the synovial fluid of patients with active disease. ${ }^{2}{ }^{3}$ In the peripheral blood of these patients, however, the levels of complement factors are normal or increased, ${ }^{4-7}$ owing to their behaviour as acute phase reactants. ${ }^{8}$ Thus an increased synthesis compensates for the accelerated catabolism of these factors, explaining why their levels do not reliably reflect complement consumption in rheumatoid arthritis. ${ }^{9}$

Unequivocal evidence of complement activation can be obtained by the measure of complement fragments which are generated during complement activation. ${ }^{10}$ Levels of the fragment C3d are found

Accepted for publication 13 August 1988.

Correspondence to Dr D Vergani, Department of Immunology, King's College School of Medicine and Dentistry, Denmark Hill, London SE5 8RX. to be raised in rheumatoid arthritis, and their increase is not confined to the synovial fluid but is 3 . also detectable in the plasma. ${ }^{711} 12$ Moreover, the levels of C3d tend to correlate with the severity of the disease. ${ }^{6} 13$

Using a recently developed technique ${ }^{14}$ we mea-? sured plasma levels of $\mathrm{C} 4 \mathrm{~d}$, a fragment produced as $\underset{O}{\mathrm{O}}$ a consequence of the early activation events of the classical complement pathway, ${ }^{15}$ in patients with $\tilde{N}$ rheumatoid arthritis with different degrees of dis- $N$ ease activity. In these patients we also determined the circulating levels of $\mathrm{C} 3 \mathrm{~d}, \mathrm{C} 4, \mathrm{C} 3$, and immune ${ }^{\omega}$ complexes and calculated the ratios $\mathrm{C} 4 \mathrm{~d} / \mathrm{C} 4$ and $\mathrm{C} 3 \mathrm{~d} / \mathrm{C} 3$, indices of complement activation indepen- dent of the initial concentration of intact comple- $\infty$ ment components.

\section{Subjects and methods}

S U B JECTS

Seventy seven patients $\left(60\right.$ female, mean age $53^{\circ}$ years, range $30-80$ years) with classical or definite 8 
rheumatoid arthritis according to the American Rheumatism Association criteria ${ }^{16}$ were studied. They were consecutive patients attending an established outpatient clinic at the department of rheumatology of King's College Hospital, London. Their mean disease duration was 9.2 years and ranged from 1.5 to 31 years. Ritchie's articular index, a simple scoring system of joint tenderness, ${ }^{17}$ was used for the clinical assessment of disease activity. Each patient underwent clinical examination by the same observer (ASMJ) at the time that blood was taken. Thirty one patients with an articular index between 1 and 7 were assigned to disease activity group 1 (mildly active group), 29 patients with an articular index between 8 and 17 to group 2 (moderately active group), and 17 patients with an articular index exceeding 17 to group 3 (severely active group). Thirty healthy individuals (12 female, mean age 36 years, range 24-46 years), members of laboratory staff at King's College Hospital, were studied as controls.

\section{BLOOD COLLECTION}

Blood $(5 \mathrm{ml})$ collected by venepuncture in a final concentration of edetic acid of $10 \mathrm{mmol} / \mathrm{l}$ was immediately separated by centrifugation at $1000 \mathrm{~g}$ at $4^{\circ} \mathrm{C}$ for 15 minutes and the plasma stored at $-70^{\circ} \mathrm{C}$. Another $5 \mathrm{ml}$ of blood was allowed to clot at room temperature for two hours; after centrifugation serum was stored at $-70^{\circ} \mathrm{C}$. All laboratory investigations were performed by an operator unaware of clinical data.

\section{C4d AND C 3 d MEASUREMENT}

C4d levels were determined by a laser nephelometric technique. ${ }^{14}$ Briefly, plasma was brought to $12 \%$ final concentration of polyethylene glycol 6000 and centrifuged at $1500 \mathrm{~g}$ for 30 minutes at $4^{\circ} \mathrm{C}$. This manoeuvre precipitates $\mathrm{C} 4$ and its larger fragments, leaving $\mathrm{C} 4 \mathrm{~d}$ in the supernatant. The concentration of $\mathrm{C} 4 \mathrm{~d}$ was then measured by laser nephelometry, using anti-C4 intact antiserum (Behring). C3d plasma levels were similarly measured using anti-C3d antiserum (Dakopatts). ${ }^{18} \mathrm{C} 4 \mathrm{~d}$ and $\mathrm{C} 3 \mathrm{~d}$ results were expressed as percentages of a $100 \% \mathrm{C} 4 \mathrm{~d}$ and $\mathrm{C} 3 \mathrm{~d}$ standard, obtained by exhaustive activation of complement through the classical pathway. Serial dilutions of the standard provided the C4d and C3d reference curves against which test samples were read.

\section{C4 AND C 3 MEASUREMENT}

Serum concentrations of $\mathrm{C} 4$ and $\mathrm{C} 3$ were determined by laser nephelometry, using specific antisera (Behring), according to the manufacturer's instructions. Results were expressed in grams per litre, using a protein calibrator distributed in the United Kingdom, consisting of pooled normal human serum (SPSO1).

MEASUREMENT OF CIRCULATING IMMUNE COMPLEXES

Serum levels of circulating immune complexes were determined by the ${ }^{125} \mathrm{I} \mathrm{Clq}$ binding assay in liquid phase. ${ }^{19}$ Results were expressed in micrograms per millilitre, using a WHO standard reference preparation containing tetanus toxoid-antitetanus toxoid complexes.

STATISTICAL ANALYSIS

Mean values of complement indices and circulating immune complexes of patients and controls were compared by Student's $t$ test. The mean values of the three patient subgroups and controls were compared using an analysis of variance method, and a test for linear trend was performed over the four groups. Correlation between complement indices and circulating immune complexes was evaluated using Pearson's analysis.

To lessen the problem of unequal variances logarithmic transformations of all the above parameters, except $\mathrm{C} 4$ and $\mathrm{C} 3$, were used throughout the study.

Statistical computations were performed using the statistical package for the social sciences (SPSS) on an Amdahl 5980/300 at the University of London Computer Centre.

Table 1 Comparison of complement indices between subgroups of patients and controls

\begin{tabular}{lcll}
\hline \multicolumn{4}{c}{ Analysis of variance } \\
\cline { 2 - 4 } & $\begin{array}{l}\text { Overall } \\
\text { analysis of } \\
\text { variance } \\
\left(F_{3 \cdot 103}\right)\end{array}$ & $\begin{array}{l}\text { Test for } \\
\text { linear trend } \\
\left(F_{1 \cdot 103}\right)\end{array}$ & $\begin{array}{l}\text { Departure from } \\
\text { linear trend } \\
\left(F_{2 \cdot 103}\right)\end{array}$ \\
\hline C4 & $9 \cdot 4^{* *}$ & $13 \cdot 2^{* *}$ & \\
C4d & $29 \cdot 5^{* *}$ & $62 \cdot 7^{* *}$ & $1 \cdot 5^{* *}$ \\
C4d/C4 & $7 \cdot 0^{* *}$ & $17 \cdot 6^{* *}$ & $1 \cdot 8^{* *}$ \\
C3 & $10 \cdot 9^{* *}$ & $18 \cdot 9^{* *}$ & $6 \cdot 8^{*}$ \\
C3d & $15 \cdot 7^{* *}$ & $35 \cdot 9^{* *}$ & $5 \cdot 6^{*}$ \\
C3d/C3 & $6 \cdot 0^{* *}$ & $15 \cdot 2^{* *}$ & $1 \cdot 4 \dagger$ \\
CIC $¥$ & $28 \cdot 3^{* *}$ & $82 \cdot 9^{* *}$ & $1 \cdot 0 \dagger$ \\
\hline
\end{tabular}

${ }^{*} 0.001<\mathrm{p}<0.01 ;{ }^{* *} \mathrm{p}<0.001$.

+ Not significant.

$\ddagger \mathrm{CIC}=$ circulating immune complexes.

$F_{3-103}$ statistic summarises the overall analysis of the groups. The larger its value, the greater the evidence against the null hypothesis that the group means are equivalent. $F_{1 \cdot 103}$ and $F_{2 \cdot 103}$ statistics should be considered together in assessing the type of trend (linear or non-linear) across the groups. Low values of both suggest no trend, whereas high values for $F_{1 \cdot 103}$ and low values for $F_{2 \cdot 103}$ support a linear trend. 

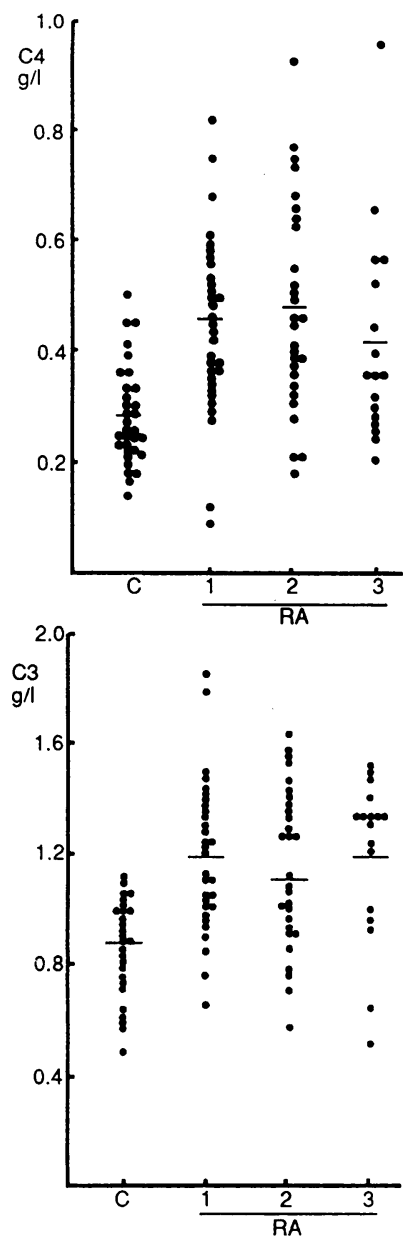
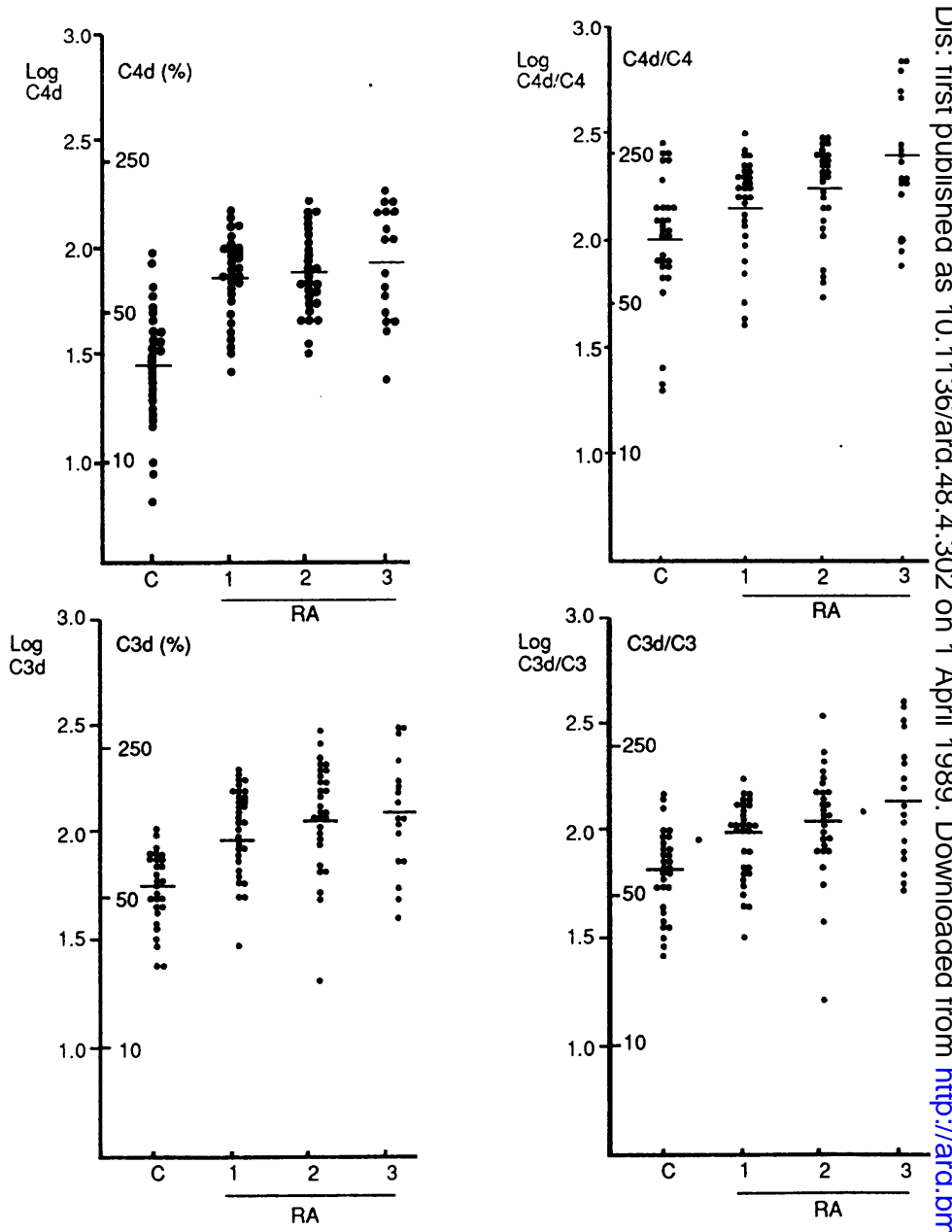

Fig. 1 Complement indices $(C 4, C 4 d, C 4 d / C 4, C 3, C 3 d, C 3 d / C 3)$ in subgroups of patients and controls. Both log $\bigcirc$ transformed and raw values are given on the vertical axis for C4d,C4d/C4,C3d, and C3d/C3. Horizontal bars represent the mean values. $C=$ controls; $R A 1 ; R A 2 ; R A 3=$ subgroups of patients with increasing grades of disease 3 activity (see text).

\section{Results}

Table 1 and Fig. 1 show the results obtained. All complement indices were significantly higher in patients with rheumatoid arthritis than in controls (C4: $t=5.18 ; C 4 d: t=9.39 ; C 4 d / C 4: t=4 \cdot 32 ; C 3$ : $t=5 \cdot 71 ; C 3 d: t=6 \cdot 77 ; C 3 d / C 3: t=3.98$; for all $\mathrm{p}<0.001$ ) and they were significantly correlated with disease activity (Table 1 ). Only the ratios $\mathrm{C} 4 \mathrm{~d} / \mathrm{C} 4$ and $\mathrm{C} 3 \mathrm{~d} / \mathrm{C} 3$ increased in proportion to the grade of disease activity without significant deviation from linear trend. That is, $\mathrm{C} 4 \mathrm{~d} / \mathrm{C} 4$ and $\mathrm{C} 3 \mathrm{~d} / \mathrm{C} 3$ values $\mathrm{N}$ were higher in the most active group (group 3 ) than in group 2 , in group 2 they were higher than in groupe 1 , and in group 1 they were higher than in controls $\mathbb{D}$ (Fig. 1).

Circulating immune complexes were significantly higher in patients than in controls. They also $\frac{\mathrm{P}}{\mathbb{Q}}$ correlated with disease activity without significant deviation from linear trend (Table 1).

A correlation was found between $\mathrm{C} 4 \mathrm{~d}$ and $\mathrm{C} 3 \mathrm{~d} \sigma$ $(\mathrm{r}=0.29, \mathrm{p}<0.01)$ and between $\mathrm{C} 4 \mathrm{~d} / \mathrm{C} 4$ and $\mathrm{C} 3 \mathrm{~d} / \mathrm{C} 3{ }_{\Omega}$ 
$(\mathrm{r}=0 \cdot 25, \mathrm{p}<0 \cdot 02) . \mathrm{C} 4 \mathrm{~d}$ and $\mathrm{C} 4 \mathrm{~d} / \mathrm{C} 4$ also correlated with circulating immune complexes $(r=0 \cdot 23, p<0.03$ and $\mathrm{r}=0.28, \mathrm{p}<0.01$ respectively).

\section{Discussion}

The present study demonstrates the value of measuring the complement fragments $\mathrm{C} 4 \mathrm{~d}$ and $\mathrm{C} 3 \mathrm{~d}$ and calculating their ratios to the parent molecule in the assessment of disease activity in rheumatoid arthritis. This is of interest, as an improvement in objective testing of disease severity would aid the management of patients with this condition.

In rheumatoid arthritis tissue injury and clinical manifestations result, at least in part, from formation and deposition of antigen-antibody complexes. ${ }^{20}$ Levels of immune complexes, which reflect this central pathogenic mechanism, would be expected to be reliable markers of disease activity, therefore. High levels of circulating immune complexes are a common finding in patients with rheumatoid arthritis, ${ }^{21}{ }^{22}$ especially in those with the most severe disease. ${ }^{6}$ Our data corroborate these observations and show that levels of circulating immune complexes increase linearly with the degree of disease activity.

Immune complexes incite tissue damage by virtue of their ability to activate complement and so initiate an inflammatory reaction. ${ }^{23}$ It is by fixing $\mathrm{C} 1 \mathrm{q}$ that immune complexes trigger the complement cascade through the classical pathway with production of the fragments $\mathrm{C} 4 \mathrm{~d}$ and $\mathrm{C} 3 \mathrm{~d} .{ }^{15}$ In keeping with this pathogenetic sequence, the measurement of $\mathrm{C} 4 \mathrm{~d}$ and $\mathrm{C} 3 \mathrm{~d}$ and the calculation of their ratios to the parent molecule not only provided evidence of complement involvement in our patients but also gave an indication of the grade of disease activity. Furthermore, a significant correlation was observed between $\mathrm{C} 4 \mathrm{~d}$ and $\mathrm{C} 4 \mathrm{~d} / \mathrm{C} 4$ values and the levels of circulating immune complexes, between the levels of $\mathrm{C} 4 \mathrm{~d}$ and $\mathrm{C} 3 \mathrm{~d}$, and between the ratios $\mathrm{C} 4 \mathrm{~d} / \mathrm{C} 4$ and C $3 \mathrm{~d} / \mathrm{C} 3$, showing that in rheumatoid arthritis complement activation proceeds through the classical pathway, immune complexes having a major role in initiating it. No correlation was observed between $\mathrm{C} 3 \mathrm{~d}$ and $\mathrm{C} 3 \mathrm{~d} / \mathrm{C} 3$ and circulating immune complexes. This could be explained by the fact that cleavage of C3 is a relatively late event in the sequence of complement activation, also influenced by alternative pathway function, while cleavage of $\mathrm{C} 4$ represents an early event in classical pathway activation, immediately following immune complex mediated C1qrs conversion. ${ }^{15}$

An interesting finding of this study is that among the indices of complement activation only the ratios $\mathrm{C} 4 \mathrm{~d} / \mathrm{C} 4$ and $\mathrm{C} 3 \mathrm{~d} / \mathrm{C} 3$ could discriminate between patients grouped according to the severity of their condition. This may be because levels of the fragments $\mathrm{C} 4 \mathrm{~d}$ and $\mathrm{C} 3 \mathrm{~d}$ are activation indices affected by the initial levels of their parent molecules and not exclusively reflecting the catabolic turnover of $\mathrm{C} 4$ and $\mathrm{C} 3$, but the fragment to parent molecule ratios are indices of activation independent of the concentration of intact components. Of relevance in this context are the reports showing that the $\mathrm{C} 4 \mathrm{~d} / \mathrm{C} 4$ and $\mathrm{C} 3 \mathrm{~d} / \mathrm{C} 3$ ratios best reflect the in vivo fractional catabolic rate of $\mathrm{C} 4$ and $\mathrm{C} 3 .^{24} 25$

In agreement with previous studies ${ }^{4-7}$ levels of $\mathrm{C} 4$ and $\mathrm{C} 3$ were not reduced in any of our patients, indicating that the measurement of intact complement factors fails to identify complement activation in rheumatoid arthritis. Nevertheless, C4 and C3 were found to correlate with disease activity, though in a non-linear relationship. This loose association with disease activity could be explained by the fact that in rheumatoid arthritis levels of $\mathrm{C} 4$ and $\mathrm{C} 3$ mirror the reactive increase ${ }^{8}$ in the production of these proteins rather than their consumption, which is the phenomenon more closely related to the pathogenesis of the disease.

In conclusion, our data show that indices of activation of the classical complement pathway, and in particular the ratios $\mathrm{C} 4 \mathrm{~d} / \mathrm{C} 4$ and $\mathrm{C} 3 \mathrm{~d} / \mathrm{C} 3$, provide a sensitive measurement of disease activity in rheumatoid arthritis. Additionally, the close correlation observed between levels of circulating immune complexes and indices of $\mathrm{C} 4$ activation, and between the latter and grades of disease activity, confirms the major part played by the classical complement pathway in the pathogenesis of this disorder.

We are indebted to Dr D Lowe for statistical advice, and to Dr D Cooper and Mrs D Shears for computing assistance. Dr G Senaldi is supported by Fondazione Anna Villa Rusconi, Varese, Italy.

\section{References}

1 Ruddy S. Plasma proteins effector of inflammation: complement. In: Kelley W N, Harris E D Jr, Ruddy S, Sledge C B, eds. Textbook of rheumatology. 2nd ed. Philadelphia: Saunders, 1985: $1042-70$.

2 Gabay R, Micheli A, Fallet G H. Behaviour of synovial complement $\mathrm{C} 3$ and $\mathrm{C} 4$ components in inflammatory and degenerative joint diseases, before and after synoviorthesis. Ann Rheum Dis 1975; 34: 166-70.

3 Ruddy S, Fearon D T, Austen K F. Depressed synovial fluid levels of properdin factor $B$ in patients with rheumatoid arthritis. Arthritis Rheum 1975; 18: 289-95.

4 Vaughan J H, Bayles T B, Favor C V. Serum complement in rheumatoid arthritis. Am J Med Sci 1951; 222: 186-92.

5 Shubert A F, Ewald R W, Schroeder W C. Serum complement levels in rheumatoid arthritis. Ann Rheum Dis 1965; 24: 439-50.

6 Mallya R K, Vergani D. Tee D E H, et al. Correlation in rheumatoid arthritis of concentrations of plasma $\mathrm{C} 3 \mathrm{~d}$, serum rheumatoid factor, immune complexes and $\mathrm{C}$-reactive protein 
with each other and with clinical features of disease activity. Clin Exp Immunol 1982; 48: 747-53.

7 Mollnes T E, Lea T, Mellbye O L, Pahle J, Grand O, Harboe $M$. Complement activation in rheumatoid arthritis evaluated by C3dg and the terminal complement complex. Arthritis Rheum 1986; 29: 715-21.

8 Colten H R. Complement biosynthesis. Clinical Immunology and Allergy 1985; 5: 287-300.

9 Ruddy S, Carpenter C B, Chin K W, et al. Human complement metabolism: an analysis of 144 studies. Medicine (Baltimore) 1975; 54: 165-78.

10 Cooper N R, Nemerow G R, Meyers J T. Methods to detect and quantitate complement activation. Seminars in Immunopathology 1983; 6: 173-94.

11 Nydegger U E, Zubler R H, Gabay R, et al. Circulating complement breakdown products in patients with rheumatoid arthritis: correlation between plasma $\mathrm{C} 3 \mathrm{~d}$, circulating immune complexes and clinical activity. $J$ Clin Invest 1977; 59: 862-8.

12 Berkowicz A, Kappelgaard E, Petersen J, et al. Complement $\mathrm{C} 3 \mathrm{c}$ and $\mathrm{C} 3 \mathrm{~d}$ in plasma and synovial fluid in rheumatoid arthritis. Acta Pathol Microbiol Immunol Scand [C] 1983; 91: 397-402.

13 Morrow W J W, Williams D J P, Ferec C, et al. The use of C3d as a means of monitoring clinical activity in systemic lupus erythematosus and rheumatoid arthritis. Ann Rheum Dis 1983; 42: 668-71.

14 Davies E T, Nasaruddin B A, Alhaq A, Senaldi G, Vergani D. Clinical application of a new technique measuring C4d for the assessment of activation of the classical complement pathway. $J$ Clin Pathol 1988; 41: 143-7.

15 Cooper N R. The complement system. In: Stites D P, Stobo J D, Wells V J, eds. Basic and clinical immunology. 6th ed. East Norwalk: Appleton and Lange, 1987: 114-27.

16 Ropes M W, Bennett G A, Cobb S, Jacox R, Jessar R A.
Revision of diagnostic criteria for rheumatoid arthritis. Bu Rheum Dis 1958; 9: 175-6.

17 Ritchie D M, Boyle J A, McInnes J M, et al. Clinical studie with an articular index for the assessment of joint tenderness ifP patients with rheumatoid arthritis. $Q J$ Med 1968; 147: 393-40)6

18 Vergani D, Bevis L, Nasaruddin B A, Mieli-Vergani G, Te D E H. Clinical application of a new laser nephelometris technique to measure complement activation. J Clin Pathos 1983; 36: 793-9.

19 Zubler R H, Lang G, Lambert P H, Miescher P A. Detection of immune complexes in untreated sera by a modified ${ }^{125} \mathrm{I} \mathrm{C}_{10}(S)$ binding test. J Immunol 1976; 116: 232-5.

20 Bennett J C. The etiology of rheumatoid arthritis. In: Kelley W N, Harris E D Jr, Ruddy S, Sledge C B, eds. Textbook of rheumatology. 2nd ed. Philadelphia: Saunders, 1985: 879-86ळ

21 Zubler R H, Nydegger U E, Perrin L H, et al. Circulating and intraarticular immune complexes in patients with rheumatoid arthritis. J Clin Invest 1976; 57: 1308-19.

22 Visher T L, Veys E, Symoens J, Rosenthal M, Huskinson E C Levamisole in rheumatoid arthritis. A randomised double-blind study comparing two dosage regimens of levamisole wits placebo. Lancet 1978; ii: $1007-12$.

23 Dixon F J. Mechanisms of immunologic injury. In: Good R A? Fisher D W, eds. Immunobiology. Stamford: Sinauer Associates, 1971: 161-6.

24 Milgrom H, Curd J G, Kaplan R A, Muller-Eberard H J Vaughan $\mathrm{J}$ H. Activation of the fourth component of comple ment (C4): assessment by rocket immunoelectrophoresis an 60 correlation with the metabolism of C4. J Immunol 1980; 124:0 2780-5.

25 Swaak A J G, Van Rooyen A, Vogelaar C, Pillay M, Hack EO Complement (C3) metabolism in systemic lupus erythematosus in relation to the disease course. Rheumatol Int 1986; 6: 221-60 